\title{
Orthogeriatrics: a vital requirement for improving fragility fracture patient care internationally with particular reference to Turkey
}

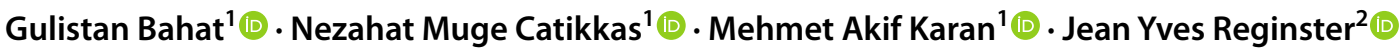

Received: 2 April 2021 / Accepted: 14 June 2021

(c) International Osteoporosis Foundation and National Osteoporosis Foundation 2021

\begin{abstract}
Purpose Orthogeriatrics is a team approach that aims to provide adequate and timely intervention for individuals suffering from fragility fractures, particularly hip fractures. These patients are mostly the frailest older adults. The aim of orthogeriatrics is to re-gain functionality as early as possible and to decrease disability and mortality. Some developed countries have established orthogeriatric services, while many others, including Turkey, have so far not. Here, to identify areas for improvement, we outline the status of the orthogeriatrics in older adults in Turkey.

Methods We present clear calls for action, emphasizing possible and noteworthy areas for improvement.

Results Our proposals include the need for an easily applied, short version of comprehensive geriatric assessment; appropriate laboratory testing on admission; paracetamol with a special emphasis in its dosings and clues for state-of-the-art analgesic management; the essential need to introduce oral nutritional supplementation, irrespective of nutritional status; the need for vitamin D commencement, in almost all patients; and starting osteoporosis treatment in fracture hospitalization, whenever appropriate. Last but not least, the ever-increasing prerequisite to establish "fracture liaison services" is stipulated.

Conclusion We suggest that our recommendations offer great potential in Turkey, for the improvement of frail fracture patients' care. We call the other countries that do not have established orthogeriatric lines to model our approach to improve the management of fracture patients globally.
\end{abstract}

Keywords Orthogeriatrics $\cdot$ Improve $\cdot$ Care $\cdot$ Fragility fracture $\cdot$ Turkey

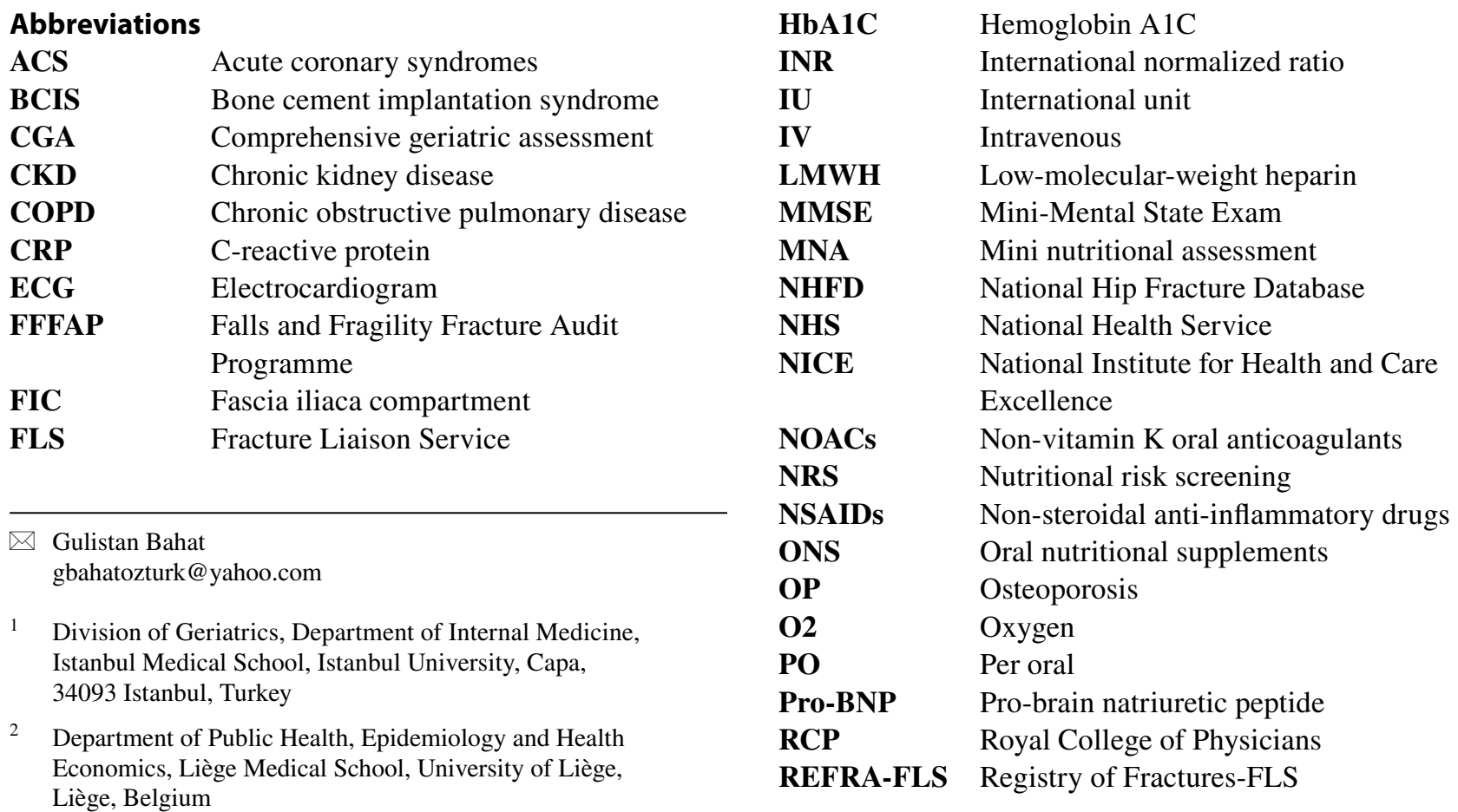




$\begin{array}{ll}\text { TIME } & \text { Turkish inappropriate medication use } \\ \text { VRS } & \text { Verbal rating scale } \\ \text { WHO } & \text { World Health Organization } \\ \text { 5-HT3 } & \text { 5-Hydroxytryptamine 3 }\end{array}$

\section{Introduction}

A significant global increase in hip and other fragility fractures is imminent, constituting a substantial burden to societies and health systems. Incidences of hip fracture are projected to increase by $310 \%$ in men and $240 \%$ in women by 2050 [1]. The decrease in intrinsic capacity is expected to increase dependency rates [2]. Orthogeriatrics is a team approach, the objective of which is to provide adequate and timely intervention for individuals suffering from fragility fractures, particularly hip fractures. Some developed countries have established orthogeriatric services, while many others, including Turkey, have so far not. In this article, our aim is to outline the status of orthogeriatrics in older adults in Turkey in order to identify areas for improvement and thereby represent a practical model for those regions where orthogeriatrics is not developed. We present clear calls for action, emphasizing possible and noteworthy areas for improvement.

\section{What is orthogeriatrics?}

Orthogeriatrics is a multidisciplinary team approach, the aim of which is to provide adequate and timely intervention opportunities for fragility fracture patients who are mostly frail and very complex. This approach could implement optimal treatment, rehabilitation, and secondary prevention of further falls and fractures [3, 4]. The aim is to re-gain the functionality and quality of life to pre-fracture levels if possible, thereby decreasing disability and mortality [5].

To date, the collaboration of orthopedics and geriatrics has been implemented in the Nordic countries (i.e., Norway, Denmark, Finland, Sweden), Scotland, Australia, New Zealand, the USA, Canada, Germany, Spain, the UK, the Netherlands, Italy, Brazil, China, North Africa, Colombia, Israel, Singapore, India, Korea, Switzerland, and Ireland. Some other countries (Hong Kong, Malaysia, Lebanon, Iran, France, Mexico, Japan) including Turkey have also made some endeavors in this field $[4,5]$. It is estimated that the number of hip fractures could increase twofold by 2025 and more than threefold by 2050 [6]. While hip fracture audits are relatively established in many regions of the world, other fragility fractures are also supervised, albeit less commonly. This is mainly due to the difficulty of detecting cases that do not require frequent hospitalization. Fracture registry systems have been developed to investigate vertebral fractures in the UK, fractures (fragility and non-fragility) in Sweden, and periprosthetic and peri-implant fractures in Germany [4]. There are many missed opportunities, particularly in the developing countries and even in some developed countries.

In a systematic review, the highest incidence rates of hip fracture were observed in Denmark (574/100.000), Norway (563/100.000), and Sweden (539/100.000) [7]. The orthogeriatric approach is proven to be cost-effective, resulting in a better mobility status, functionality, quality of life, lower fear of falling, and consequent hospital admissions $[8,9]$. The length of hospitalization and mortality are also decreased [10]. In a study, the risk ratio for the prevention of falls was 1.15 with orthogeriatric care, when compared with ordinary orthopedic care [11]. In another study, a reduction in recurrent falls was reported in the enhanced interdisciplinary inpatient rehabilitation and care model group [4]. By contrast, evidence for the effect of orthogeriatric care on fall prevention, falls, and subsequent fracture rates is still insufficient and inconclusive. In this regard, more studies are needed to determine whether orthogeriatric approach may reduce falls and secondary fractures [12].

This interdisciplinary team includes an orthopedist, geriatrician, anesthetist, nurse, physiotherapist, dietician, social worker, occupational therapist, and clinical pharmacist [5]. The geriatrician acts to decrease and manage perioperative comorbidities and complications; handle drug therapy, coping with inappropriate medication use/polypharmacy; assess falls; and manage osteoporosis (OP) [5]. As individuals who suffer from hip fractures are mostly elderly and have potential cognitive impairments and a very high fall risk, inpatient services should be organized to counteract delirium and falls and to encourage mobilization [5].

Different orthogeriatric models have been acknowledged to improve outcomes for hip fracture patients [12]. In Model 1 , patients are admitted to an orthopedic unit. Orthopedic surgeons have overall responsibility, while the geriatricians are consultants. In Model 2, patients are admitted to a geriatric unit. Geriatricians have overall responsibility, while the orthopedic surgeons are consultants. In Model 3, patients are admitted to an integrated unit with shared care. Both the orthopedic surgeons and geriatricians share responsibility. A meta-analysis has identified a significant decrease in long-term mortality, in-hospital mortality, time to surgery, lower postop delirium, and improved function with Model 1 [12]. In another study examining the effects of a dedicated geriatric unit on the mortality in older adults with hip fractures, both mortality and re-hospitalization risks were shown to be significantly decreased compared to the orthopedic cohort, even after adjustment for age, gender, and comorbidities [13]. A recent meta-analysis identified that older adults with hip fractures, admitted early into a dedicated orthogeriatric ward, had reduced long-term mortality [14]. Although there are only limited studies to provide a better 
overview, the geriatric orthopedic co-management model (Model 3) is regarded as the latest trend [5, 10].

\section{Components of orthogeriatric care}

\section{1) Preoperative care}

\section{i. Hospitalization and radiological examinations}

Clinicians should evaluate the fall event; functionality before the event; consciousness level; possible head trauma and other fractures sites; the possibility of concurrent infection; stroke; anemia; arrhythmia; heart/respiratory failure; dehydration; malnutrition; polypharmacy; and alcohol consumption [5]. In Turkey, orthopedic surgeons commonly focus on the trauma and other possible sites of fracture, stroke, and other systemic problems. Yet, fall assessment, malnutrition, polypharmacy, and alcohol consumption are not evaluated regularly.

\section{ii. Blood and urine analysis and electrocardiogram}

Clinicians should request comprehensive routine blood tests [hemogram; C-reactive protein (CRP); kidney, liver, and thyroid function tests; electrolytes; 25-hydroxy vitamin D level, B12, and folic acid]. Close electrolyte monitoring should be performed in malnourished patients in terms of the risk of refeeding syndrome. Also, the following tests should be requested in the specified situations: hemoglobin A1C (HbA1C) in diabetic patients, pro-brain natriuretic peptide (Pro-BNP) in suspected heart failure, troponin in acute coronary syndrome, and international normalized ratio (INR) in those using warfarin. Spot urine analysis should be performed in all patients, and if a urinary infection is suspected, a urine culture should be obtained [5]. Electrocardiogram (ECG) must be performed on hospital admission [5]. According to our observations from the 2 centers in our country where the orthogeriatric approach is applied, while these are commonly utilized in Turkey, spot urine analysis is commonly overlooked with a subsequent failure to perform a culture test when required.

\section{iii. Preoperative evaluation}

Preoperative evaluation by a geriatrician is preferred. However, if the geriatrician is not available, the operation should not be delayed [5]. An early operation, within 1-2 days with subsequent mobilization, reduces mortality in hip fracture patients $[4,15]$. Norwegian guidelines recommend operation within the first $48 \mathrm{~h}$ and the National Institute for Health and Care Excellence (NICE) guidelines for the English and Welsh National Health Service (NHS), within $36 \mathrm{~h}$. To ensure optimal conditions, the operation should not be postponed [4]. In Turkey, the number of geriatricians is limited; however, internal medicine specialists are widely available. Even so, their education on the geriatrics approach is limited. Also, in locations where geriatricians are available, orthopedic surgeons do not commonly seek geriatric evaluation, and the focus is mostly on prompt surgery and immediate surgery success. We suggest that orthopedic surgeons request comprehensive evaluations for each inpatient presenting with hip fractures, if these are available, from a geriatrician or otherwise from an internal medicine specialist. Comprehensive geriatric assessment (CGA) has an important role in reducing the risk of complications and post-discharge mortality in older adults with hip fracture [4]. Comprehensive geriatric assessment should include brief assessments of the following: pain [with verbal rating scale (VRS)]; malnutrition [with nutritional risk screening (NRS)2002 score]; delirium (with 4AT test); cognition [with MiniMental State Exam (MMSE)]; urinary incontinence; falls; and sleep disorders $[4,5]$.

\section{iv. Pain management}

The patient should be managed to be painless or with mild pain at rest and mild/ moderate pain upon moving. Clinicians should be attentive in the management of cognitively severely impaired individuals and those unable to speak. In these patients, increased respiratory rate, restlessness, resistance to posture changes, painful facial expressions, crying, and delirium constitute the pain indicators [5]. The basic principle is to treat pain with paracetamol and nerve blockade and to supplement with opioids only if necessary [4, 5]. Surgery may be the best analgesic method, as it relieves pain [5].

\section{Analgesics}

- Paracetamol

Paracetamol is the gold-standard analgesic medication in this scenario. The recommended dose is $4 \times 1 \mathrm{~g}$ per oral (po)/intravenous (iv), while the first dose should be $2 \mathrm{~g}$ if the bodyweight is $>60 \mathrm{~kg}$. If the bodyweight is $<60 \mathrm{~kg}$, the loading dose should be $1.5 \mathrm{~g}$ routinely followed by $3 \times 1 \mathrm{~g}$ po/iv. Of note, paracetamol should be used cautiously in case of hepatic failure. The dose should be reduced after 14 days in individuals older than 80 years and who have very low body weight [5].

- Opioids

This is not the first choice, given their frequent hazardous adverse effects. Side effects are common, serious, and wide-range, i.e., respiratory depression, urinary 
retention, nausea, constipation, fall tendency, and delirium [5]. If required, clinicians should commence morphine in the lowest effective dosage. Morphine should be used with caution in renal failure. In this context, oxycodone may be an alternative. If adverse effects appear, switching to an alternative is performed because side effect profiles vary between opioids. Naloxone should be considered in titrated doses in case of overdose [5]. Meperidine is unacceptable due to neurotoxicity and delirium risks, especially in chronic renal failure, which is very prevalent among fragility fracture patients [16]. Tramadol can cause severe problems like convulsions, serotonergic syndrome, and hypoglycemia. Accordingly, clinicians should avoid tramadol, which only may be given in titrated doses $[5,17]$. Oxycodone, hydromorphone, morphine, fentanyl, and buprenorphine may be alternatives [16].

- Non-steroidal anti-inflammatory drugs (NSAIDs)

These are potent analgesics; however, they are not recommended in standard therapy in these patients, considering prevalent renal failure, hypovolemia, gastrointestinal bleeding risk, heart failure, hypertension, and cardiovascular diseases [5]. They have the potential to delay fracture healing [18] and are rarely suggested for older adults, being only a cautious alternative if pain management is inadequate and others are not tolerated [5].

In Turkey, paracetamol is not commonly used for pain management due to its underappreciated analgesic effect in higher doses. The alcohol consumption rate is low between the ages of 18 and 60 in our country (7.8\%) [19]. Also, between the ages of 65 and 74, the rate for men is $11.2 \%$ and $1.3 \%$ for women, while the rate is $4.4 \%$ for men and $0.5 \%$ for women aged 75 and over [20]. Furthermore, according to the "Global Alcohol and Health Report" published by the World Health Organization (WHO) in 2014, the consumption of alcohol in Turkey is lower than in many other countries [21]. In this context, alcohol consumption is usually not a major problem among older Turkish adults. Paracetamol is generally well-tolerated if there is no factor contributing to paracetamol toxicity, such as liver failure (related with, e.g., hepatitis B, C, and chronic liver disease), drug use causing hepatotoxicity; or advanced age, and very low weight [22]. Yet, NSAIDs are used liberally with consequential adverse events, some of which are recognized, e.g., renal failure and gastrointestinal bleeding, but some are not recognized, i.e., cardiovascular events.

- Peripheral nerve blockade

Local nerve block is increasingly being used for the management of pain. NICE guidelines report that nerve block should be used whenever possible to limit the use of systemic analgesics. Both femoral nerve and fascia iliaca compartment (FIC) blocks are shown to be efficacious in hip fractures. These are recommended in cases of severe pain as they reduce the use and side effects of opioids preoperatively $[4,5,23,24]$.

\section{v. Antithrombotic therapy}

Non-vitamin K oral anticoagulants (NOACs) do not increase perioperative bleeding and mortality [25]. They should be ceased $24-48 \mathrm{~h}$ before spinal anesthesia. The international normalized ratio (INR) should be $<1.5$ in warfarin users, prior to spinal intervention [4]. Clopidogrel, ticagrelor, and prasugrel users cannot be given spinal anesthesia, but aspirin and dipyridamole are safe [5].

Low-molecular-weight heparin (LMWH) (subcutaneous) once a day and generally thigh-length vs. knee-length antiembolic stockings are recommended for deep vein thrombosis prophylaxis during hospitalization [4]. The American Association of Clinical Pharmacy guidelines recommend LMWH use, lasting for 10-14 days, up to 35 days [26].

In Turkey, antithrombotic pharmacologic therapy is mostly managed in line with guidelines. Knee-high antiembolic stockings are commonly employed as there are compliance problems with thigh-high stockings.

\section{vi. Anesthesia}

The routine method is spinal anesthesia with bupivacaine; however, general anesthesia may be preferred in line with the patient or surgeon's preference or if contraindications for spinal anesthesia, i.e., a risk of bleeding, the use of dual anticoagulants, previous dorsal surgery, or local pathology are present [4].

Spinal anesthesia is generally preferred in Turkey, if available. If it is not, general anesthesia is used.

\section{vii. Other essentials in the preoperative period}

Vital functions should be monitored four times a day and, in high-risk patients, peripheric oxygen saturation two times a day. Fluid balance should be followed by using a urinary catheter on postoperative day one. Constipation is common, and prophylactic laxatives should be given if needed. Urinary incontinence medications should be discontinued until mobilization. Upon the removal of the bladder catheter, residual urine should be assessed via bladder scanning. Medications should be managed, taking into consideration polypharmacy, fall risk (especially. for antihypertensives, alpha-blockers, and opioids), and delirium risk (especially 
anticholinergics, sedatives) [5]. Neuroleptics via extrapyramidal side effects, benzodiazepines via sedation and balance disorders, and Z-type hypnotics via sedation and ataxia are not advised in most patients due to high fall risk [16].

In Turkey, most of the above measures are taken; however, constipation is commonly overlooked with a failure to commence routine laxatives in these risky individuals. Urinary catheters are used for longer periods with subsequent development of related complications. While this may be needed in sacral pressure sore cases, it is not removed in many cases without a valid indication. Residual urine screening following catheter removal is usually not performed; catheters are sometimes only removed just prior to discharge. Medications are not commonly managed because they are mostly related to various accompanying chronic internal diseases and geriatric syndromes. Surgeons do not consider medicines due to their limited experience in these conditions and focus mainly on immediate surgery and discharge. In our country, clinicians have Turkish inappropriate medication use (TIME) criteria specifically developed for use in Eastern Europe [16]. This has been validated by an international expert group and can be used through Europe [27]. A mobile application (TIME application) has been released very recently (www.timecriteria.com). Using this application, surgeons have the opportunity to screen for inappropriate medication use.

Malnutrition screening is one of the most important actions. Individuals should be served energy and proteinrich meals [5]. It should be noted that in hip fracture patients, oral nutritional supplements (ONS) should be started regardless of malnutrition risk/malnutrition status [16]. Preoperative fasting should be kept to a minimum if possible. Preoperative ONS may be considered in patients with a waiting period $>4-6 \mathrm{~h}$. In the preoperative period, patients should stop solid foods only $6 \mathrm{~h}$ and clear liquids $2 \mathrm{~h}$ beforehand [4]. Clinicians should review risk factors for delirium. All patients should be screened daily and assessed with standardized tools to avoid delirium being missed. The 4AT, a simple scoring with good reliability, is a useful tool for recognizing and screening delirium (www.the4AT.com). It does not require special training and has been validated in hip fracture patients [28]. While neuroleptic prophylaxis is not recommended, haloperidol (0.25-2 mg oral or intramuscular) can be used in the presence of hazardous agitation in a hyperactive delirium state. It should be commenced with a low dose, and the daily dose should not exceed $5 \mathrm{mg}$. Lower doses should be used for patients with dementia and frailty $[4,5]$. If there is no efficacy after $2-4$ doses, olanzapine $(2.5-10 \mathrm{mg}$ oral $)$ and risperidone $(0.5-2 \mathrm{mg}$ oral) can be given. All these drugs are contraindicated in the presence of QT prolongation [4, 5]. Because of extrapyramidal side effects, haloperidol is contraindicated in Parkinson's disease, Lewy body disease, and other Parkinsonism disorders [5, 16]. In such diseases, instead of haloperidol, quetiapine (12.5-50 mg) may be an alternative. Likewise, hypoactive delirium should not be overlooked. Neuroleptics are not used in hypoactive delirium [5]. Sleep problems are common for a variety of reasons. In this case, besides non-pharmacological approaches, melatonin is the supplement of choice. Pressure sores may develop in risky individuals, and measures for prevention/treatment should be commenced [5]. Each and every patient should be provided with a special pressure-relieving mattress, accompanied by position changes at regular intervals, while the operated leg is kept in 30 degrees of abduction [29].

Nutritional screenings are conducted before surgeries as a public health policy in Turkey, as recommended by the Ministry of Health. Even so, there is still a failure to implement a nutritional plan even when a nutritional problem is detected. While there are some attempts to limit the preoperative fasting state, many centers implement an overnight fasting order the day before the surgery. Oral supplements are rarely used and then only in the limited number of centers that are endeavoring to integrate orthogeriatric practice. A common pitfall is sleep problems, for which attempts are often made to solve them with benzodiazepines or neuroleptics, the use of which invites additional problems. Pressure-relieving mattresses are uniformly applied throughout the country, but nursing care with position changes is dependent on the center with widespread practical differences.

Another issue is the management of cardiovascular problems. Troponin monitoring may be complex in patients at high risk of acute coronary syndromes (ACS) because troponin may be elevated in falls owing to muscle injury. Therefore, close ECG monitoring and troponin follow-ups are recommended in case of ACS suspicion [5]. Postoperative atrial fibrillation is common, and beta-blockers should be continued during hospitalization. Respiratory problems should be assessed, as should vigilance for and the treatment of postoperative mucus plugs [5]. Chronic obstructive pulmonary disease (COPD) exacerbations are common [5]. Blood loss by surgery and transfusion need should be considered with a hemoglobin target of $9-10 \mathrm{~g} / \mathrm{dl}$ in cardiac disease and cerebral and pulmonary dysfunction [5]. Hypoxia should be assessed, and oxygen (O2) supplementation should be provided if saturation is below 95\% [4]. Of note, prophylactic $\mathrm{O} 2$ is not recommended [5]. First-generation cephalosporin group antibiotic, which is preferably iv cefazolin, should be commenced for surgical prophylaxis $[30,31]$. Clindamycin and vancomycin can be alternatives if there is a beta-lactam allergy [31]. Clinicians can use a validated hip fracture risk stratification tool, such as the Nottingham Hip Fracture Score, to predict the risk of 30-day mortality (Table 1) [32]. 
Table 1 The Nottingham hip fracture score [32]

\begin{tabular}{llcc}
\hline Variable & Points & Total score & $\begin{array}{r}\text { Predicted 30-day post- } \\
\text { operative mortality (\%) }\end{array}$ \\
\hline Age 66-85 years & 3 & 0 & $\mathbf{0 . 4}$ \\
Age 86 years or older & 4 & 1 & $\mathbf{0 . 6}$ \\
Male & 1 & 2 & $\mathbf{1 . 0}$ \\
Hb less than or equal to 10 g dl on admission to hospital & 1 & 3 & $\mathbf{1 . 7}$ \\
Abbreviated mental test score $\leq \mathbf{6 / 1 0}$ at hospital admission & 1 & $\mathbf{2 . 9}$ \\
Living in an institution & 1 & $\mathbf{4 . 7}$ \\
More than one comorbidity* & 1 & $\mathbf{7 . 6}$ \\
Active malignancy within last 20 years & 1 & $\mathbf{1 2 . 3}$ \\
Total score & & 7 & $\mathbf{1 8 . 2}$ \\
& & 8 & $\mathbf{2 7 . 0}$ \\
\hline
\end{tabular}

A score out of ten is calculated by adding the scores for the eight criteria in the left column. The total score is used to estimate a patient's mortality risk within 30 days after hip fracture surgery (right column). Comorbidities $\left(^{*}\right)$ include myocardial infarction, angina, atrial fibrillation, valvular heart disease, hypertension, cerebrovascular accident, transient ischemic attack, asthma, chronic obstructive pulmonary disease, and renal dysfunction

In Turkey, cardiovascular and respiratory problems are recognized and commonly consulted with the corresponding specialists. However, hip fracture risk stratification tools are not commonly introduced.

Areas for improvement Countries should review the components of orthogeriatric care to improve the management of fragility hip fractures and decrease the burden of fracture-related impaired functionality, quality of life, hospitalizations, mortality, and cost. We outlined the review results for Turkey above and clear and simple actions for improvement below, as a model.

Box 1 Areas for improvement in the preoperative care of fragility fracture patients.

Assessment of fall events, malnutrition, polypharmacy, and alcohol consumption to be evaluated regularly

Spot urine analysis and urine culture in case of urinary infection suspicion to be ordered on hospital admission

Geriatric approach and education to be introduced widely

Preoperative FIC blockade to be considered in practice

Paracetamol to be considered a gold-standard pharmacological agent for pain, used in its sufficient dose

NSAIDs and opiates to be avoided if possible

Preferably apply thigh-length anti-embolic stockings

Spinal anesthesia to be widely introduced when appropriate

Urinary catheters limited to postoperative day one unless there is a

high risk for sacral pressure sore

Medications to be managed with a holistic approach; TIME criteria application can be useful

ONS to be started regardless of malnutrition risk/malnutrition status

Manage sleep problems by non-pharmacological approaches and melatonin

Early operation attempts, within 1-2 days, to be improved Hip fracture risk stratification tools to be introduced

$F I C$, fascia iliaca compartment; $L M W H$, low-molecular-weight heparin; NSAIDs, non-steroidal anti-inflammatory drugs; ONS, oral nutritional supplementation; $O P$, osteoporosis; TIME, Turkish inappropriate medication use in elderly.

\section{2) Postoperative care}

Following surgery, adequate fluid and nutrient intake, physiological defecation, micturition, and pain control should be ensured. Early mobilization should be attempted, and delirium should be closely monitored [5]. Orthostatic hypotension is common in this setting. It is very common among older adults. Also, prolonged immobilization, anesthetics used within the surgery, and anticholinergics promote orthostatism. Accordingly, orthostatism should be assessed after gaining the ability to stand still for $3 \mathrm{~min}$ [5]. Postoperative nausea is common. Metoclopramide and trimethobenzamide should be avoided due to their extrapyramidal side effects; domperidone should be avoided due to adverse cardiac events [16, 33]. Serotonin 5-HT3 (5-hydroxytryptamine 3 ) receptor antagonists are the drug of choice [5].

Optimal protein intake is essential for wound healing and muscle strengthening to help counteract falls in the followup. The ideal amount is 1.0-1.5 g/day in older adults unless they are in the pre-dialysis period. During periods of acute stress, a protein supply of up to $2 \mathrm{~g} /$ day may be considered, if there is no severe kidney failure [16]. The PROT-AGE working group reported the required protein intake for older adults with chronic kidney disease (CKD), based on ideal body weight. In severe CKD (GFR, $<30 \mathrm{ml} / \mathrm{min} / 1.73 \mathrm{~m}^{2}$ ), protein intake should be limited to $0.8 \mathrm{~g} / \mathrm{kg} / \mathrm{day}$; in moderate CKD (GFR, 30-60 $\mathrm{ml} / \mathrm{min} / 1.73 \mathrm{~m}^{2}$ ), protein intake should be $>0.8 \mathrm{gr} / \mathrm{kg} / \mathrm{day}$, but GFR should be checked twice a year; in mild CKD (GFR, $>60 \mathrm{ml} / \mathrm{min} / 1.73 \mathrm{~m}^{2}$ ), protein intake may be increased according to the patient's needs. Protein intake $>1.2 \mathrm{~g} / \mathrm{kg} / \mathrm{day}$ ( $>1.5 \mathrm{~g} / \mathrm{kg} /$ day, if achievable) is recommended for hemodialysis or peritoneal dialysis patients 
[34]. Optimal protein intake prevents bone loss after orthopedic surgery, increases muscle strength, reduces complications, and shortens hospitalization and rehabilitation [35]. Optimal energy is needed for protein to be used in recovery rather than as a source of energy. A caloric intake of $30 \mathrm{kcal} /$ $\mathrm{kg}$ /day forms the basis to start in most cases and can be modified in the follow-ups by nutritional assessments $[16,36]$. Calcium and vitamin D are vital for bone health and repair. Most fragility fracture patients lack adequate calcium and vitamin D intake. Vitamin D measurement is costly and may not be available in most locations. Therefore, commencing vitamin $\mathrm{D}$ treatment as cholecalciferol is recommended. The optimal intake is $800-1000 \mathrm{IU} / \mathrm{d}$ but can be given up to the upper tolerable limit of vitamin D, i.e., 4.000 IU/day [4, 16, 37]. However, in a 12-month double-blind, randomized controlled trial, the effects of various daily vitamin $\mathrm{D}$ doses on falls were examined in postmenopausal women (age range, 57-90 years) with baseline serum $25(\mathrm{OH})$ D vitamin levels of $20 \mathrm{ng} / \mathrm{ml}$ or less. Participants were asked to maintain a $1200-1400 \mathrm{mg} /$ day of calcium intake, and if they could not increase dietary calcium to those levels, a calcium supplement (mean, $580 \mathrm{mg}$ ) was given. The fall rates at high doses such as 4.000 and 4.800 IU/day of vitamin D were significantly higher than at doses of 1.600-3.200 IU/day. In this regard, in older women, especially those with a history of falls, the safe upper limit for vitamin D supplementation may be narrower than previously described $[38,39]$. Elementary calcium is required at 1000-1200 mg/day dose and is preferably taken with regular meals [4, 40]. However, if the diet is insufficient, the advice is for it to be supplemented at about $500 \mathrm{mg} /$ day [40].

Osteoporosis treatment should be started during hospitalization for fracture, given the reports appraising beneficial and non-hazardous osteoporosis medications when commenced in this state. Studies have shown that the early administration of bisphosphonates within the first 2 weeks after fracture does not delay fracture healing [4, 5, 41-44]. In cases where vitamin $\mathrm{D}$ is sufficient, and there is no other contraindication, oral bisphosphonates, zoledronic acid, and denosumab within the first 2 weeks and teriparatide within the first week after the fracture, during the hospitalization, can be started $[4,5]$.

Bone cement implantation syndrome (BCIS) is a rare complication that may cause $0.5 \%$ of cardiopulmonary arrest in surgeries integrating instruments and/or femoral cement fixation [4]. This should be considered during the postoperative period.

In postoperative management, the overall aim is to limit the length of hospital stay to a short a time as possible, to limit in-hospital complications [5]. Moreover, to achieve the best results in the long-term, clinicians are expected to introduce optimal care measures in this period.

In this country, delirium is generally unrecognized by non-geriatricians/non-psychiatrists, as well as orthopedics staff. Postoperative orthostatism is seldomly considered and assessed. When nausea is encountered, mostly metoclopramide/trimethobenzamide is introduced. Nutritional needs are, unfortunately, seldom considered, which generally results in a lack of optimum protein, calcium, and vitamin D intake. Many fracture patients suffer from vitamin D deficiency, and treatment to combat osteoporosis is commonly disregarded. Orthopedics focuses on early discharge to limit in-hospital complications while on occasions missing optimal care opportunities for best functional outcomes.

Fracture liaison services (FLSs) are established to commence necessary osteoporosis treatment and the best possible care to prevent falls and subsequent fractures in those suffering from a fragility fracture [45]. The main elements involve identifying those patients, individualized assessment, treatment planning, maintenance, and follow-ups tailored to the needs of an individual case [46, 47]. Its scope is obviously the acutely hospitalized fragility fracture patients. It is beneficial and cost-effective. By managing falls and osteoporosis, these services are invaluable for reducing repeated fractures [48, 49]. A hip fracture audit is relatively established in some regions in the world, but an audit of other fragility fractures is less common. It is difficult to detect fractures that do not require hospital admission/hospitalization. Consequently, many vertebral fractures go clinically undetected $[50,51]$. Further audit research is now focusing on FLS databases; for example, there is one in England under the auspices of the Royal College of Physicians (RCP), as part of the same Falls and Fragility Fracture Audit Programme (FFFAP), together with the National Hip Fracture Database (NHFD) [52], and also in Canada with 45 FLSs, in 2018 [53]. Spain is currently piloting a fragility fracture and FLS audit, the Spanish Registry of FracturesFLS (REFRA-FLS), with the participation of over a dozen hospitals [54].

In our country, FLSs are currently limited and are only available in Cerrahpaşa Medical Faculty Hospital, Fatih Sultan Mehmet Training and Research Hospital, Ankara City Hospital, and Medicana International Ankara Hospital (https://www. capturethefracture.org/index.php/map-of-best-practice).

The first comprehensive orthogeriatric care concept to operate in Turkey was at Istanbul University Istanbul Medical School, followed by Istanbul Prof. Dr. Cemil Taşçığlu City Hospital. As comprehensive orthogeriatric care has only been applied in two centers, our data illustrate only a 2-center approach. In this regard, orthogeriatrics in 
Turkey has several more steps to climb to achieve optimum application.

Box 2 Areas for improvement in the postoperative care of fragility fracture patients.

Delirium to be considered and recognized

Orthostatic hypotension to be assessed after gaining the ability to stand still for $3 \mathrm{~min}$

Nausea, if encountered, to be managed by 5 -HT3 receptor antago-

nists; metoclopramide/trimethobenzamide to be avoided

Protein intake (1.0-1.5 g/kg/d unless in pre-dialytic state), energy

(30 kcal/d), calcium (1000-1200 mg/d), and vitamin D intake

$(1000 \mathrm{IU} / \mathrm{d})$ be provided in osteoporotic older patients

Anti-osteoporotic medications to be commenced during fracture

hospitalization, if appropriate

Fracture liaison services to be established in more centers

Orthogeriatric models to be widely implemented

$d$, day; 5-HT3, 5-hydroxytryptamine 3 .

\section{Conclusion}

We have outlined the orthogeriatric care concept and presented the current, commonly applied management protocol in Turkey. In so doing, we have identified several, nonetheless very valuable, areas for improvement. This study represents a practical model for countries where orthogeriatrics remains undeveloped. We have presented clear calls for action, emphasizing areas requiring significant improvement. We suggest that our recommendations offer great potential for the improvement of fragility fracture patient care in Turkey. Also, we call on other countries to model our approach to improve the management of fracture patients globally.

Author contribution Bahat G, Catikkas NM, Karan MA, and Reginster JY contributed to the study. Bahat $G$ and Catikkas NM contributed to the study design. Bahat $\mathrm{G}$ and Catikkas NM did literature review. Bahat G, Karan MA, and Reginster JY did the critical review. All co-authors read and approved the final version of the manuscript.

Availability of data and material The data is available from the authors upon reasonable request.

Code availability N/A.

\section{Declarations}

Conflicts of interest Gulistan Bahat has received a speaker honorarium from the companies LILLY and AMGEN. Nezahat Muge Catikkas has no conflicts of interest to declare that are relevant to the content of this article. Mehmet Akif Karan has no conflicts of interest to declare that are relevant to the content of this article. Jean Yves Reginster has received consulting fees or paid advisory boards from these companies: IBSAGenevrier, Mylan, Radius Health, Pierre Fabre, Faes Farma, Rejuvenate Biomed, Samumed, Teva, Theramex, Pfizer, and Mithra Pharmaceuticals. He has received lecture fees when speaking at the invitation of sponsors from these companies: IBSA-Genevrier, Mylan, CNIEL, Dairy
Research Council (DRC), Nutricia, Danone, and AgNovos. He also has received grant support from industry (all through institution): IBSAGenevrier, Mylan, CNIEL, Radius Health, and TRB.

\section{References}

1. IOF 2020. https://www.osteoporosis.foundation/health-profession als/fragility-fractures/epidemiology. Accessed 24 June 2021

2. Reginster J, Cooper C, Kanis J, Schneider M, Bruyère O, Rizzoli R (2017) Capture the fracture: integrated care prevents the decrease in intrinsic capacity in elderly subjects. Innov Aging 1(Suppl 1):692. Published 2017 Jun 30. https://doi.org/10.1093/ geroni/igx004.2478

3. Wilson H (2017) Orthogeriatrics in Hip Fracture. Open Orthop J 11:1181-1189. Published 2017 Oct 31

4. Falaschi P, March D (2021) Orthogeriatrics. The management of older patients with fragility fractures. Second Edition. ISBN 978-3-030-48125-4 ISBN 978-3-030-48126-1 (eBook). https:// doi.org/10.1007/978-3-030-48126-1.

5. Ranhoff AH, Saltvedt I, Frihagen F, Raeder J, Maini S, Sletvold O (2019) Interdisciplinary care of hip fractures. Orthogeriatric models, alternative models, interdisciplinary teamwork. Best Pract Res Clin Rheumatol 33(2):205-226

6. Gullberg B, Johnell O, Kanis JA (1997) World-wide projections for hip fracture. Osteoporos Int 7:407-413

7. Kanis JA, Odén A, McCloskey EV, Johansson H, Wahl DA, Cooper C, IOF Working Group on Epidemiology and Quality of Life (2012) A systematic review of hip fracture incidence and probability of fracture worldwide. Osteoporos Int. 23(9):2239-56. https://doi.org/10.1007/s00198-012-1964-3

8. Sletvold O, Helbostad JL, Thingstad P et al (2011) Effect of inhospital comprehensive geriatric assessment (CGA) in older people with hip fracture. The protocol of the Trondheim Hip Fracture trial. BMC Geriatr. 11:18

9. Watne LO, Torbergsen AC, Conroy S, Engedal K, Frihagen F, Hjorthaug GA, Juliebo V, Raeder J, Saltvedt I, Skovlund E, Wyller TB (2014) The effect of a pre- and postoperative orthogeriatric service on cognitive function in patients with hip fracture: randomized controlled trial (Oslo Orthogeriatric Trial). BMC Med 15(12):63. https://doi.org/10.1186/1741-7015-12-63

10. Grigoryan KV, Javedan H, Rudolph JL (2014) Orthogeriatric care models and outcomes in hip fracture patients: a systematic review and meta-analysis. J Orthop Trauma 28(3):e49-55

11. Kristensen PK, Thillemann TM, Søballe K, Johnsen SP (2016) Can improved quality of care explain the success of orthogeriatric units? A population-based cohort study. Age Ageing 45(1):66-71. https://doi.org/10.1093/ageing/afv155

12. Van Camp L, Dejaeger M, Tournoy J, Gielen E, Laurent MR (2020) Association of orthogeriatric care models with evaluation and treatment of osteoporosis: a systematic review and meta-analysis. Osteoporos Int 31(11):2083-2092. https://doi.org/10.1007/ s00198-020-05512-y

13. Boddaert J, Cohen-Bittan J, Khiami F, Le Manach Y, Raux M, Beinis JY, Verny M, Riou B (2014) Postoperative admission to a dedicated geriatric unit decreases mortality in elderly patients with hip fracture. PLoS ONE 9(1):e83795. https://doi.org/10. 1371/journal.pone.0083795

14. Moyet J, Deschasse G, Marquant B, Mertl P, Bloch F (2019) Which is the optimal orthogeriatric care model to prevent mortality of elderly subjects post hip fractures? A systematic review and meta-analysis based on current clinical practice. Int Orthop 43(6):1449-1454

15 Moja L, Piatti A, Pecoraro V, Ricci C, Virgili G, Salanti G, Germagnoli L, Liberati A, Banfi G (2012) Timing matters in hip 
fracture surgery: patients operated within 48 hours have better outcomes. A meta-analysis and meta-regression of over 190,000 patients. PLoS One. 7(10):e46175. https://doi.org/10.1371/journ al.pone. 0046175

16. Bahat G, Ilhan B, Erdogan T, Halil M, Savas S, Ulger Z, Akyuz F, Bilge AK, Cakir S, Demirkan K, Erelel M, Guler K, Hanagasi H, Izgi B, Kadioglu A, Karan A, Kulaksizoglu IB, Mert A, Ozturk S, Satman I, Sever MS, Tukek T, Uresin Y, Yalcin O, Yesilot N, Oren MM, Karan MA (2020) Turkish inappropriate medication use in the elderly (TIME) criteria to improve prescribing in older adults: TIME-to-STOP/TIME-to-START. Eur Geriatr Med 11(3):491-498. https://doi.org/10.1007/s41999-020-00297-z

17. Makunts T, Andrew U, Atayee RS, Abagyan R (2019) Retrospective analysis reveals significant association of hypoglycemia with tramadol and methadone in contrast to other opioids. Sci Rep 9(1):12490. https://doi.org/10.1038/s41598-019-48955-y

18 Giannoudis PV, MacDonald DA, Matthews SJ, Smith RM, Furlong AJ, De Boer P (2000) Nonunion of the femoral diaphysis. The influence of reaming and non-steroidal anti-inflammatory drugs. J Bone Joint Surg Br 82(5):655-8. https://doi.org/10.1302/ 0301-620x.82b5.9899

19. Bahat G, Turkmen BO, Aliyev S, Catikkas NM, Bakir B, Karan MA (2021) Cut-off values of skeletal muscle index and psoas muscle index at L3 vertebra level by computerized tomography to assess low muscle mass. Clin Nutr S0261-5614(21)00020-0. https://doi.org/10.1016/j.clnu.2021.01.010

20. Özcan B, Sever S (2017) Sosyo-Demografik Değişkenler Açısından Alkol Kullanımı ve Çeşitli Kriterlere Göre Analizi. Bilecik Şeyh Edebali Üniversitesi Sosyal Bilimler Dergisi 2(1):261276. Retrieved from https://dergipark.org.tr/tr/pub/bseusbed/issue/ 30015/292073. Accessed 24 June 2021

21. WHO (2014) Global status report on alcohol and health.

22. Yoon E, Babar A, Choudhary M, Kutner M, Pyrsopoulos N (2016) Acetaminophen-induced hepatotoxicity: a comprehensive update. J Clin Transl Hepatol 4(2):131-42. https://doi.org/10.14218/ JCTH.2015.00052

23. NICE guidance: the management of hip fractures in adults (2017) Page 36. https://www.nice.org.uk/guidance/cg124/evidence/fullguideline-pdf-183081997. Accessed 24 June 2021

24. Pain management in elderly fracture. Orthogeriatrics-Clinical Summary Document. AO Foundation. https://aotrauma.aofou ndation.org//media/project/aocmf/aotrauma/documents/educa tion_pdf/curriculum/aot_orthogeriatrics_painmanagement.pdf? la $=$ en\&hash $=$ DD5B3BFCC6E66EF4F9E0B478CFE0DC19969 DAB6F. Accessed 24 June2021

25. Mullins B, Akehurst H, Slattery D, Chesser T (2018) Should surgery be delayed in patients taking direct oral anticoagulants who suffer a hip fracture? A retrospective, case-controlled observational study at a UK major trauma centre. BMJ Open 8(4):e020625

26. Flevas DA, Megaloikonomos PD, Dimopoulos L, Mitsiokapa E, Koulouvaris P, Mavrogenis AF (2018) Thromboembolism prophylaxis in orthopaedics: an update. EFORT Open Rev 3(4):136-148. https://doi.org/10.1302/2058-5241.3.170018

27. Bahat G, İlhan B, Erdogan T, Oren MM, Karan MA, Burkhardt $\mathrm{H}$ et al (2021) International validation of the Turkish inappropriate medication use in the elderly. Drugs Aging.https://doi.org/10. 1007/s40266-021-00855-5(inpress)

28. Bellelli G, Morandi A, Davis DH, Mazzola P, Turco R, Gentile S, Ryan T, Cash H, Guerini F, Torpilliesi T, Del Santo F, Trabucchi M, Annoni G, MacLullich AM (2014) Validation of the 4AT, a new instrument for rapid delirium screening: a study in 234 hospitalised older people. Age Ageing 43(4):496-502. https:// doi.org/10.1093/ageing/afu021. Erratum in: Age Ageing. 2015 Jan;44(1):175
29. National Pressure Ulcer Advisory Panel, European Pressure Ulcer Advisory Panel and Pan Pacific Pressure Injury Alliance (2014) Prevention and treatment of pressure ulcers: clinical practice guideline. Emily Haesler (Ed.). Cambridge Media: Osborne Park, Western Australia

30. Bhatti NS, Ertl JP (2019) Hip fracture medication. Drugs \& Diseases, Sports Medicine

31. Bratzler DW, Dellinger EP, Olsen KM, Perl TM, Auwaerter PG, Bolon MK, Fish DN, Napolitano LM, Sawyer RG, Slain D, Steinberg JP, Weinstein RA, American Society of Health-System Pharmacists; Infectious Disease Society of America; Surgical Infection Society; Society for Healthcare Epidemiology of America (2013) Clinical practice guidelines for antimicrobial prophylaxis in surgery. Am J Health Syst Pharm 70(3):195-283. https://doi.org/10. 2146/ajhp120568

32. Marufu TC, White SM, Griffiths R, Moonesinghe SR, Moppett IK (2016) Prediction of 30-day mortality after hip fracture surgery by the Nottingham hip fracture score and the surgical outcome risk tool. Anaesthesia 71:515-552

33. Cincin AT, Ilhan B, Bahat G, Karan MA (2016) Possible side effects of metoclopramide. Clin Nutr 35(4):975

34. Bauer J, Biolo G, Cederholm T, Cesari M, Cruz-Jentoft AJ, Morley JE, Phillips S, Sieber C, Stehle P, Teta D, Visvanathan R, Volpi E, Boirie Y (2013) Evidence-based recommendations for optimal dietary protein intake in older people: a position paper from the PROT-AGE Study Group. J Am Med Dir Assoc 14(8):542-559. https://doi.org/10.1016/j.jamda.2013.05.021

35. Bonjour JP (2011) Protein intake and bone health. Int J Vitam Nutr Res 81(2-3):134-142. https://doi.org/10.1024/0300-9831/ a000063

36. Volkert D, Beck AM, Cederholm T, Cruz-Jentoft A, Goisser S, Hooper L, Kiesswetter E, Maggio M, Raynaud-Simon A, Sieber CC, Sobotka L, van Asselt D, Wirth R, Bischoff SC (2019) ESPEN guideline on clinical nutrition and hydration in geriatrics. Clin Nutr 38(1):10-47. https://doi.org/10.1016/j.clnu.2018.05.024

37. Institute of Medicine. Report at a glance. Report brief: dietary reference intakes for calcium and vitamin $\mathrm{D}$, released 11/30/2010. http://www.iom.edu/Reports/2010/Dietary-Reference-Intakes-forCalcium-and-Vitamin-D/Report-Brief.aspx (Accessed on December 01, 2010).

38 Rizzoli R (2021) Vitamin D supplementation: upper limit for safety revisited? Aging Clin Exp Res 33(1):19-24. https://doi. org/10.1007/s40520-020-01678-x

39. Smith LM, Gallagher JC, Suiter C (2017) Medium doses of daily vitamin D decrease falls and higher doses of daily vitamin D3 increase falls: a randomized clinical trial. J Steroid Biochem Mol Biol 173:317-322. https://doi.org/10.1016/j.jsbmb.2017.03.015

40. Kirazlı Y, AtamazÇalış F, El Ö, GökçeKutsal Y, Peker Ö, Sindel D, Tuzun Ş, GogasYavuz D, Durmaz B, Akarirmak Ü, Bodur H, Hamuryudan V, Inceboz U, Öncel S (2020) Updated approach for the management of osteoporosis in Turkey: a consensus report. Arch Osteoporos 15(1):137. https://doi.org/10.1007/ s11657-020-00799-0

41. Barton DW, Smith CT, Piple AS, Moskal SA, Carmouche JJ (2020) Timing of bisphosphonate initiation after fracture: what does the data really say? Geriatr Orthop Surg Rehabil. https://doi. org/10.1177/2151459320980369

42 Seton M (2010) How soon after hip fracture surgery should a patient start bisphosphonates? Cleve Clin J Med 77(11):751-755. https://doi.org/10.3949/ccjm.77a.10045

43. Li YT, Cai HF, Zhang ZL (2015) Timing of the initiation of bisphosphonates after surgery for fracture healing: a systematic review and meta-analysis of randomized controlled trials. Osteoporos Int 26(2):431-441. https://doi.org/10.1007/ s00198-014-2903-2 
44 Shin Y, Shin WC, Kim JW (2020) Effect of osteoporosis medication on fracture healing: an evidence based review. J Bone Metab 27:15. https://doi.org/10.11005/jbm.2020.27.1.15

45 Stephenson S (2003) Developing an orthopaedic elderly care liaison service. J Orthop Nurs 7(150): 155

46 Berg P, Schweitzer DH, Hoard PMM, Bergh JP, Geusens PP (2015) Meeting international standards of secondary fracture prevention: a survey on fracture liaison services in the Netherlands. Osteoporos Int 26:2257-2263

47. Aizer J, Bolster MB (2014) Fracture liaison services: promoting enhanced bone health care. Curr Rheumatol Rep 16(11):455

48. Wu CH, Kao IJ, Hung WC, Lin SC, Liu HC, Hsieh MH, Bagga S, Achra M, Cheng TT, Yang RS (2018) Economic impact and cost-effectiveness of fracture liaison services: a systematic review of the literature. Osteoporos Int 29(6):1227-1242. https://doi.org/ 10.1007/s00198-018-4411-2

49. Fuggle NRI, Javaid MK, Fujita M, Halbout P, Dawson-Hughes B, Rizzoli R et al (2021) Fracture risk assessment and how to implement a fracture liaison service. In: Orthogeriatrics: The Management of Older Patients with Fragility Fractures [Internet]. Cham (CH): Springer; Chapter 14. 2020 Aug 21. https://doi.org/10.1007/ 978-3-030-48126-1_14.
50. Cooper C, Atkinson EJ, O'Fallon WM, Melton LJ (1982) Incidence of clinically diagnosed vertebral fractures: a populationbased study in Rochester, Minnesota, 1985-1989. J Bone Miner Res 7(2):221-227

51. Pizzato S, Trevisan C, Lucato P, Girotti G, Mazzochin M, Zanforlini BM, Bano G, Piovesan F, Bertocco A, Zoccarato F, Dianin M, Manzato E, Sergi G (2018) Identification of asymptomatic frailty vertebral fractures in post-menopausal women. Bone 113:89-94. https://doi.org/10.1016/j.bone.2018.05.007

52. Fracture Liaison Service Database (FLS-DB) [Internet] (2015) RCP London. https://www.rcplondon.ac.uk/projects/fracture-liais on-service-database-flsdb. Accessed 24 June 2021

53. Osteoporosis Canada (2018) Report from Osteoporosis Canada's first national FLS audit [Internet]. https://fls.osteoporosis.ca/ wpcontent/uploads/Report-from-Osteoporosis-Canadas-first-natio nal-FLS-audit.pdf. Accessed 24 June 2021

54. Registro REFRA [Internet]. Seiomm. https://seiomm.org/regis tro-refra. Accessed 24 June 2021

Publisher's note Springer Nature remains neutral with regard to jurisdictional claims in published maps and institutional affiliations. 